\title{
Highly Efficient Europium(III) Uptake with an Extraction Chromatographic Resin Containing a Unique Multiple Diglycolamide Ligand with a Tetraaza-12-crown-4 Scaffold
}

\author{
Piyali Banerjee, Seraj A. Ansari, Prasanta K. Mohapatra,* Richard J.M. Egberink, \\ Srirangaraja Ramasubramanium, Chhagan B. Patil, Jurriaan Huskens, and Willem Verboom*
}

Cite This: Ind. Eng. Chem. Res. 2021, 60, 2613-2624

Read Online

ACCESS | LلII Metrics \& More 回 Article Recommendations

ABSTRACT: An extraction chromatographic resin was prepared by impregnating Chromosorb-W with a unique ligand consisting of four diglycolamide moieties functionalized to a tetraaza-12crown-4 scaffold. This resin was evaluated for the uptake of $\mathrm{Eu}^{3+}$, as a representative of trivalent lanthanides and actinides, from moderate acid solutions. The distribution coefficient of $\mathrm{Eu}^{3+}$ on the resin was very large $\left(>1 \times 10^{4}\right)$ in the acid range 0.1-6 $\mathrm{M} \mathrm{HNO}_{3}$, and its sorption followed the pseudo-second-order kinetic model. The sorption of $\mathrm{Eu}^{3+}$ proceeded via a chemisorption phenomenon with a sorption energy of $26 \pm 2 \mathrm{~kJ} / \mathrm{mol}$. The $\mathrm{Eu}^{3+}$ sorption onto the resin was both enthalpy and entropy driven. FTIR and fluorescence measurements of the $\mathrm{Eu}^{3+}$ complex formed on the resin confirmed the chemical interaction between the $\mathrm{Eu}^{3+}$ and the ligand present on the solid support. The resin capacity was $14.4 \pm 0.1 \mathrm{mg}$ of $\mathrm{Eu}^{3+}$ per $\mathrm{g}$ of resin corresponding to the formation of a 1:1 metal/ligand complex. The sorbed $\mathrm{Eu}^{3+}$ from the resin could be efficiently desorbed with 0.1 M HEDTA ( $N$-(2-hydroxyethyl)ethylenediamine triacetic acid). The column loading of $\mathrm{Eu}^{3+}$ was $83 \%$ of the equilibrium value with a narrow elution profile. The hydrolytic and leach stability of the impregnated resin was excellent, tested in five successive cycles of loading and elution.

\section{INTRODUCTION}

Although nuclear power is considered a major source of energy in the 21 st century, its acceptance to the general public depends on various safety issues, including environmental contamination due to occasional accidents over the years. More recently, the Fukushima-Daiichi accident in Japan has near-field contamination, which needs to be efficiently monitored using matured technology. ${ }^{1}$ The common radionuclides spewed in the environment include the long-lived actinides and important fission product nuclides such as ${ }^{137} \mathrm{Cs}$, ${ }^{90} \mathrm{Sr}$, etc. In actinide fractions, apart from large concentrations of $\mathrm{U}$ and various $\mathrm{Pu}$ isotopes, there are isotopes of minor actinides such as ${ }^{237} \mathrm{~Np}\left(t_{1 / 2}: 2.1 \times 10^{6} \mathrm{y}\right),{ }^{241} \mathrm{Am}\left(t_{1 / 2}: 431 \mathrm{y}\right)$, ${ }^{243} \mathrm{Am}\left(t_{1 / 2}: 7400 \mathrm{y}\right),{ }^{243} \mathrm{Cm}\left(t_{1 / 2}: 30 \mathrm{y}\right),{ }^{244} \mathrm{Cm}\left(t_{1 / 2}: 18.1 \mathrm{y}\right)$, ${ }^{245} \mathrm{Cm}\left(t_{1 / 2}: 8532 \mathrm{y}\right)$, etc. In addition to actinides, there are a few lanthanide fission product radionuclides like ${ }^{152} \mathrm{Eu}\left(t_{1 / 2}\right.$ : $12.4 \mathrm{y})$ and ${ }^{154} \mathrm{Eu}\left(t_{1 / 2}: 8.5 \mathrm{y}\right)$, which have significantly long half-lives and require monitoring in the environment. The contaminated soil needs to be digested in acid and subjected to separation methods such as precipitation, ${ }^{2}$ solvent extraction, ${ }^{3}$ and ion exchange. ${ }^{4}$

Despite the existence of many efficient methods for the separation of radionuclides from acidic feeds, ${ }^{5}$ literature on the separation of trivalent actinides and lanthanides is still evolving. Out of the various separation methods, extraction chromatography appears to be highly promising due to the use of a very small amount of organic solvents, generation of low amounts of secondary waste, and ease of technical operation when separations are carried out in a column. ${ }^{5-8}$ Use of selective organic extractants for trivalent lanthanides and actinides such as CMPO (carbamoylmethyl phosphine oxide), ${ }^{9}$ malonamide ( $N, N^{\prime}$-dimethyl-N,N'-dibutyl tetradecyl malonamide), ${ }^{10}$ and DGA (diglycolamide) ${ }^{11-13}$ in extraction chromatographic resins has shown good results for the separation of trivalent lanthanides and actinides. Out of these extractants, the DGA extractants such as TODGA $\left(N, N, N^{\prime}, N^{\prime}\right.$-tetraoctyl diglycolamide, Figure 1a) have given very impressive results in the separation of trivalent actinides from a variety of acidic feed solutions. ${ }^{13}$

In the recent decade, a variety of multiple DGA ligands with varying structural features have been synthesized with tripodal geometries (referred to as T-DGA, Figure 1b). ${ }^{14-17}$ These ligands have shown significantly high extraction efficiency for

Received: January 14, 2021

Revised: January 19, 2021

Accepted: January 22, 2021

Published: February 4, 2021 


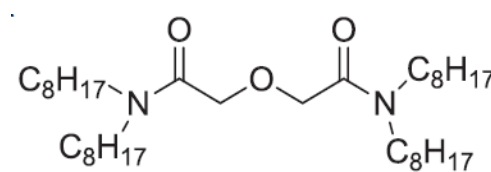

(a)

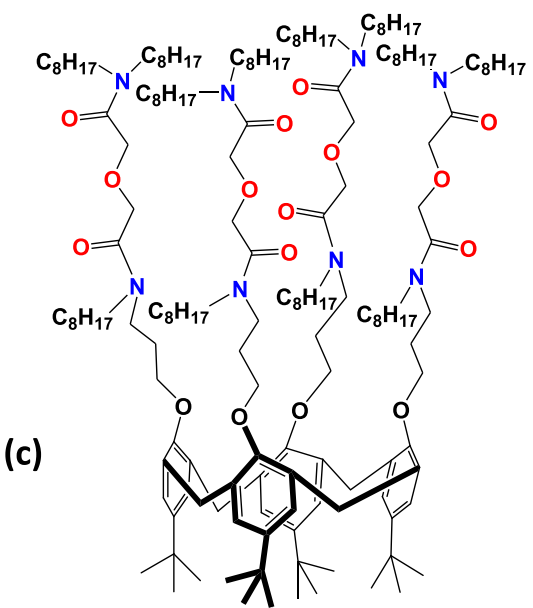

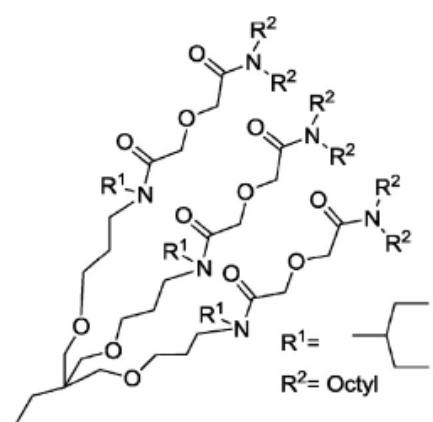

(b)

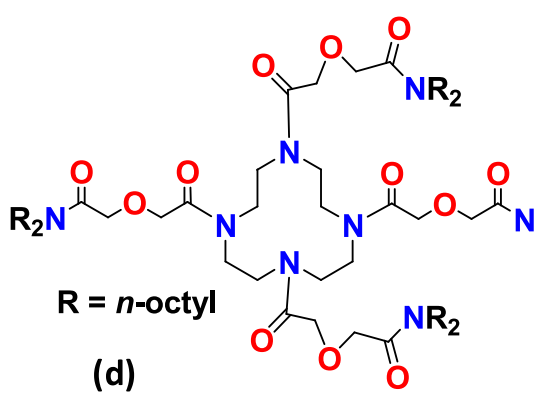

Figure 1. Structural formulas of the extractants investigated for trivalent actinides and lanthanides. (a) TODGA, (b) T-DGA, (c) C4DGA, (d) TAM-4-DGA.

trivalent actinides and lanthanides as compared to a normal DGA ligand like TODGA. These ligands have also shown better separation factors for $\mathrm{Am}(\mathrm{III})$ with respect to $\mathrm{U}(\mathrm{VI})$, $\mathrm{Sr}(\mathrm{II})$, and $\mathrm{Cs}(\mathrm{I})$. Further it was found that grafting of the DGA moieties onto macrocyclic scaffolds such as calix[4]arene (C4DGA, Figure 1c) ${ }^{18}$ and pillar[5] arene $^{19}$ gave even better results with respect to preferential extraction of trivalent actinides and lanthanides over $\mathrm{U}(\mathrm{VI}), \mathrm{Sr}(\mathrm{II})$, and $\mathrm{Cs}(\mathrm{I})$. In this series, we synthesized a unique DGA ligand where four DGA moieties (containing terminal octyl groups) were tethered to a tetraaza-12-crown-4 scaffold (termed as TAM-4-DGA, Figure 1d). ${ }^{20}$ Solvent extraction and complexation studies with TAM4-DGA ligand gave the most encouraging results for the separation of trivalent lanthanides and actinides with all DGA extractants reported to date. ${ }^{20}$ In view of this, it was of interest to prepare an extraction chromatographic resin containing TAM-4-DGA for the separation of trivalent lanthanides and actinides. The present paper deals with the preparation of extraction chromatographic resin by impregnating the TAM-4DGA ligand onto Chromosorb-W. Studies pertaining to the characterization of resin and its behavior toward sorption of $\mathrm{Eu}^{3+}$ ions were investigated in detail. $\mathrm{Eu}^{3+}$ was the choice for the present work as a representative of lanthanides and also as a surrogate for trivalent actinides.

\section{EXPERIMENTAL SECTION}

2.1. Materials. TAM-4-DGA ligand, containing four diglycolamide moieties with a terminal octyl group, anchored to a tetraaza-12-crown-4 scaffold (Figure 1d), was synthesized as per the procedure reported elsewhere. ${ }^{20}$ The purity of the ligand was checked by elemental analysis as well as NMR and HR-MS techniques and was found to be $>95 \%$. The diluents, n-dodecane (Lancaster, UK) and isodecanol (>99\%, SRL, Mumbai), were used as received. Chemicals such as $\mathrm{N}$-(2hydroxyethyl)ethylenediamine triacetic acid (HEDTA, SigmaAldrich), EDTA (Merck), and guanidine carbonate (99\%, Sigma-Aldrich) were used without any further purification. Chromosorb-W (dimethyl dichlorosilane treated acid washed Celite diatomaceous silica, particle size: 175-250 $\mu \mathrm{m}$ ) obtained from Johns Manville, USA was washed with distilled water, methanol, and acetone followed by air-drying before use. A known quantity of $\mathrm{Eu}\left(\mathrm{NO}_{3}\right)_{3} \cdot 6 \mathrm{H}_{2} \mathrm{O}$ (Sigma-Aldrich) was dissolved in $0.01 \mathrm{M}$ nitric acid to make standard $\mathrm{Eu}\left(\mathrm{NO}_{3}\right)_{3}$ solution followed by its volumetric titration with standard EDTA. ${ }^{21}$ Suprapur nitric acid (Merck, Germany) was used for the preparation of all dilute nitric acid solutions using Milli-Q water (Millipore, USA). All the other chemicals were of analytical reagent grade and were used as received. Radiotracer ${ }^{152,154} \mathrm{Eu}$ was procured from the Board of Radiation and Isotope Technology, Mumbai and used after confirming its radiochemical purity by an $\mathrm{HPGe}$ detector.

2.2. Instrumentation. Thermogravimetric analysis was performed using a Netzsch Thermobalance at a heating rate of $5{ }^{\circ} \mathrm{C}$ per minute in air atmosphere up to $1000{ }^{\circ} \mathrm{C}$ (Model: STA 409 PC Luxx). A stereoscan 100 Cambridge model SEM instrument was used for the surface morphology analysis. The analysis was performed at $15 / 25 \mathrm{kV}$ with a magnification of $3000 \times$ at a working distance of $15 \mathrm{~mm}$ at a tilt angle of $45^{\circ}$. Before the measurement, the sample was coated with gold (15 nm coating) with a Balzer's coating unit (model: CEA 30). Fluorescence emission spectra were recorded, and the fluorescence lifetime of $\mathrm{Eu}^{3+}$ was determined on a PTI QuantaMaster fluorometer (PTI QuantaMaster 400) adapted for time-resolved measurements. FTIR spectra of the solid 
Table 1. Linearized Form of Different Sorption Isotherm Models

\begin{tabular}{llll} 
Isotherm & \multicolumn{1}{c}{ Linearized form ${ }^{a}$} & Linear Plot & \multicolumn{1}{c}{ Parameters } \\
Langmuir & $\frac{C_{\mathrm{e}}}{q_{\mathrm{e}}}=\frac{[1]}{b \cdot q_{\max }}+\frac{C_{e}}{q_{\max }}$ & $\frac{C_{\mathrm{e}}}{q_{\mathrm{e}}} \mathrm{vs} C_{e}$ & $q_{\max }=1 /$ slope, $b=$ slope/intercept \\
Freundlich & $\log q_{\mathrm{e}}=\log K_{f}+\frac{1}{n} \log C_{e}$ & $\log q_{e}$ vs log $C_{e}$ & $K_{f}=$ intercept, $n=1 /$ slope \\
D-R & $\ln q_{e}=\ln q_{\max }-\beta \epsilon^{2}$ & $\ln q_{\mathrm{e}}$ vs $\varepsilon^{2}$ & $q_{\max }=$ intercept, $E=1 / 2 \beta^{0.5}($ slope $)$ \\
Temkin & $q_{\mathrm{e}}=B_{T} \ln A_{T}+B_{T} \ln C_{\mathrm{e}}$ & $q_{e}$ vs $\ln C_{e}$ & $B_{T}=$ slope, $A_{T}=$ intercept/slope
\end{tabular}

${ }^{a} q_{\mathrm{e}}=$ amount of $\mathrm{Eu}^{3+}$ sorbed per gram of resin at equilibrium; $C_{\mathrm{e}}=$ equilibrium concentration of Eu $\mathrm{u}^{3+}$ in the aqueous phase; $q_{\mathrm{max}}=$ maximum mass of $\mathrm{Eu}^{3+}$ sorbed on the resin; $K_{f}=$ maximum sorbed mass of $\mathrm{Eu}^{3+}$.

samples were recorded on a Bruker Alpha II ATR-FTIR spectrometer. Quantification of $\mathrm{Eu}^{3+}$ in the analytical samples was done using ${ }^{152,154} \mathrm{Eu}$ tracer spiking, and the latter was analyzed by a well type $\mathrm{NaI}(\mathrm{Tl})$ scintillation counter (Para Electronics) interphased with a multichannel analyzer (ECIL, India).

2.3. Preparation of the Extraction Chromatographic Resin. The extraction chromatographic resin was prepared by impregnating the TAM-4-DGA ligand on Chromosorb-W by following the method described earlier. ${ }^{22}$ The choice of Chromosorb-W as an inert solid support was due to its highly porous nature, and being a silica material, it has good radiation stability. A known weight of ligand (1 part) was dissolved in 3 parts of a $5 \%$ isodecanol $/ n$-dodecane mixture in a stoppered conical flask to obtain a uniform solution. Since the ligand was insoluble in pure $n$-dodecane, $5 \%$ isodecanol $/ n$-dodecane was used which gave a clear ligand solution. ${ }^{20}$ To this solution, 5 parts of Chromosorb-W were added to give a ligand, solvent, and solid support weight ratio of 1:3:5. Finally, ca. $20 \mathrm{~mL}$ of acetone were added to the flask and the slurry was equilibrated for $24 \mathrm{~h}$ in a mechanical shaker at 100 agitations per minute. After equilibration, the solvent (acetone) was removed carefully by flushing nitrogen gas in the flask with gentle stirring to obtain a uniform ligand impregnated resin. The resultant resin was vacuum-dried at $60-80{ }^{\circ} \mathrm{C}$ until a constant weight was obtained to afford a free-flowing resin material for subsequent use. The ligand loading on the support (calculated from the initial weight of the support, ligand and the final weight of resin) was found to be $11.1 \%(\mathrm{w} / \mathrm{w})$, which corresponded to $96.9 \mu \mathrm{mol} / \mathrm{g}$ of resin.

2.4. Distribution Coefficient Measurements. The distribution coefficient of $\mathrm{Eu}^{3+}$ ion under different experimental conditions was measured by equilibrating about $10 \mathrm{mg}$ of resin with $1 \mathrm{~mL}$ of aqueous solution. The equilibrations were performed in glass stoppered tubes in a thermostated water bath maintained at $25.0 \pm 0.1{ }^{\circ} \mathrm{C}$ for about $1 \mathrm{~h}$, which was found to be sufficient for reaching the equilibrium condition (vide infra). After equilibration, the tubes were centrifuged, and about $100 \mu \mathrm{L}$ of aqueous supernatant phase were taken out and centrifuged a second time to remove any resin particles. Suitable aliquots from the aqueous phase were removed before and after equilibration for assaying ${ }^{152,154} \mathrm{Eu}$ radiometrically. The weight distribution ratio $\left(K_{\mathrm{d}}\right)$ value of $\mathrm{Eu}^{3+}$ on the resin was calculated as

$$
K_{\mathrm{d}}=\left[\frac{\left(C_{\mathrm{o}}-C\right)}{C}\right] \cdot \frac{V}{W}\left(\mathrm{~mL} \cdot \mathrm{g}^{-1}\right)
$$

where $C$ and $C_{\mathrm{o}}$ are the concentrations of ${ }^{152,154} \mathrm{Eu}$ (in counts per unit time per unit volume) before and after equilibration. The terms $V$ and $W$ represent the volume of the aqueous phase $(\mathrm{mL})$ and the weight of the resin $(\mathrm{g})$ used, respectively. All the distribution measurements were carried out in triplicate, and the reported values are the mean values of the replicate measurements. The relative standard deviations (RSD) on the triplicate $K_{d}$ values were less than $2 \%$ for the values in the range $1-1000$. However, an $\mathrm{RSD}$ up to $7 \%$ was accepted where the $K_{\mathrm{d}}$ values were $<1$ or $>1000$.

2.5. Kinetic and Thermodynamic Studies. Kinetic experiments were performed at $0.1 \mathrm{M} \mathrm{HNO}_{3}$ by equilibrating the aqueous phase, containing a ${ }^{152,154} \mathrm{Eu}$ tracer, with $10 \mathrm{mg}$ of resin. The time of equilibrations was kept at $2-60 \mathrm{~min}$, and the amounts of ${ }^{152,154} \mathrm{Eu}$ activity (in terms of counts) sorbed per $\mathrm{g}$ of resin were recorded as a function of time. The sorption data were subsequently fitted in Lagergren pseudo-first-order and pseudo-second-order rate equations given below. ${ }^{23,24}$

$$
\begin{aligned}
& \ln \left(q_{\mathrm{e}}-q_{t}\right)=\ln q_{\max }-k_{1} \cdot t \\
& \frac{t}{q_{t}}=\frac{1}{k_{2} \cdot q_{\max }^{2}}+\frac{t}{q_{\max }}
\end{aligned}
$$

where $k_{1}=$ pseudo-first-order rate constant, $k_{2}=$ pseudosecond-order rate constant, $q_{\mathrm{e}}=$ amount of $\mathrm{Eu}^{3+}$ ions sorbed onto the resin at equilibrium, $q_{t}=$ amount of $\mathrm{Eu}^{3+}$ ions sorbed onto the resin at time $t$, and $q_{\max }=$ maximum sorption value.

The kinetic data were also treated with the Elovich model (eq 4 ) and pore diffusion model given in eq 5 .

$$
q_{t}=\frac{1}{\beta} \ln (\alpha \cdot \beta)+\frac{1}{\beta} \ln (t)
$$

Here, the terms are $\alpha=$ initial sorption rate and $\beta=$ desorption constant in the Elovich model.

$$
q_{t}=k_{\mathrm{id}} \cdot t^{0.5}+C
$$

where $k_{\mathrm{id}}=$ interparticle constant. Here, $C$ is a constant that provides information about the thickness of the aqueous film around the solid resin.

Thermodynamics studies were performed by measuring the $K_{\mathrm{d}}$ values of $\mathrm{Eu}^{3+}$ at $0.1 \mathrm{M} \mathrm{HNO}_{3}$ at different temperatures in the range $15-55{ }^{\circ} \mathrm{C}$. The equilibration time was maintained at $60 \mathrm{~min}$ to ensure that the system reached the equilibrium condition. Subsequently, the thermodynamic equilibrium constant, $K_{\mathrm{ex}}$, was calculated at different temperatures from the equilibrium reaction described later (vide infra).

2.6. Sorption Isotherm Studies. The $\mathrm{Eu}^{3+}$ sorption isotherm on the TAM-4-DGA resin was studied by measuring 
its equilibrium sorption values from varying aqueous phase concentrations of $\mathrm{Eu}\left(\mathrm{NO}_{3}\right)_{3}$. The $\mathrm{Eu}^{3+}$ sorption data were treated by fitting in several sorption isotherm models such as the Langmuir, Freundlich, Temkin, and Dubinin-Radushkevich $(D-R)$. The linear forms of these isotherm models are given in Table 1 .

2.7. Column Studies. The column was prepared by packing about $0.4 \mathrm{~g}$ of resin in a $4 \mathrm{~mm}($ dia $) \times 25 \mathrm{~mm}$ (height) glass column. Details about the preparation of column have been described in our earlier publication. ${ }^{32}$ The resin bed height in the column was $12.8 \mathrm{~cm}$ which corresponded to 1.61 $\mathrm{cm}^{3}$ of bed volume and $0.25 \mathrm{~g} / \mathrm{cm}^{3}$ of bed density. The feed solution was $0.4 \mathrm{mg} / \mathrm{mL} \mathrm{Eu}\left(\mathrm{NO}_{3}\right)_{3}$ at $3 \mathrm{M} \mathrm{HNO}_{3}$ spiked with ${ }^{152,154} \mathrm{Eu}$ tracer. A constant flow rate of $0.3 \mathrm{~mL} / \mathrm{min}$ was maintained during the $\mathrm{Eu}^{3+}$ loading, washing, and elution in the column. Preconditioning of the column was done by passing $10 \mathrm{~mL}$ of $3 \mathrm{M} \mathrm{HNO}_{3}$ before loading the feed solution.

\section{RESULTS AND DISCUSSION}

3.1. Characterization of the Resin Beads. The extraction chromatographic resin was obtained as free-flowing material with $11.1 \%(\mathrm{w} / \mathrm{w})$ loading of the extractant. The presence of the ligand was confirmed from the FT-IR spectra which clearly show the carbonyl peak (in the region 1580$1690 \mathrm{~cm}^{-1}$, Figure 2) of TAM-4-DGA (this peak was absent in

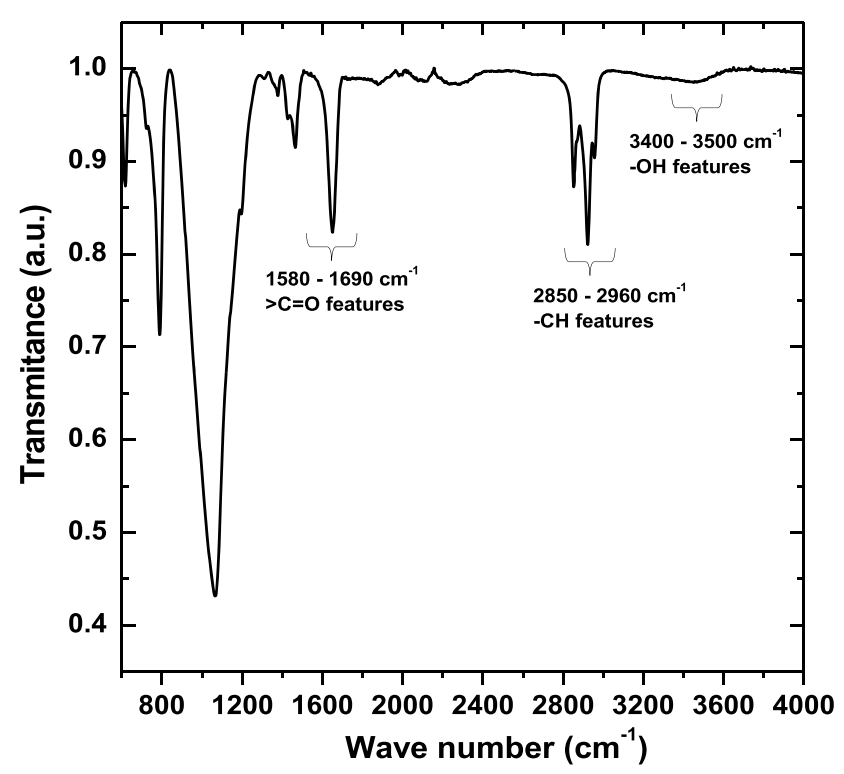

Figure 2. FT-IR spectra of the TAM-4-DGA coated Chromosorb-W resin.

the solid Chromosorb-W). The bands in the range 2850-2960 $\mathrm{cm}^{-1}$ are characteristic of the $-\mathrm{CH}-$ groups of the alkyl chain. The absence of a broad band at $>3000 \mathrm{~cm}^{-1}$ suggests the absence of any moisture in the resin. Additionally, knowledge about the surface morphology can be obtained by SEM analysis which, in turn, would be of help to understand many of its physical and chemical properties.

Surface morphology information on the TAM-4-DGA resin was obtained from the SEM photographs at $700 \times$ magnification. Figure $3 \mathrm{a}$ shows the SEM image of the pristine resin, while that of the resin after the uptake studies and regeneration after back extraction (vide infra) is presented in Figure 3b. The SEM photographs show large flakes of the Chromosorb-W with honeycomb-like structures which may assist in the extractant loading as well as water intrusion into the pores resulting in a relatively fast mass transfer. The SEM photographs of both the resins are similar suggesting no degradation of the beads. The EDX spectra of the resins (Chromosorb-W, ligand loaded extraction chromatographic material, and resin loaded with $\mathrm{Eu}^{3+}$ ions) are presented in Figure 4 which indicate the presence of $\mathrm{Eu}^{3+}$ ions in the loaded resin.

3.2. Distribution Behavior of $\mathrm{Eu}^{3+}$. The uptake of $\mathrm{Eu}^{3+}$ ions onto the extraction chromatographic resin was studied over a wide range of acidities. Figure 5a shows the $K_{d}$ values of $\mathrm{Eu}^{3+}$ ions with TAM-4-DGA resin under varying feed acidities. The $K_{\mathrm{d}}$ value increased with increasing feed acidity from 0.01 to $4 \mathrm{M} \mathrm{HNO}_{3}$ and remained very large $\left(>1 \times 10^{5}\right)$ between 3 and $6 \mathrm{M} \mathrm{HNO}_{3}$. This is a typical solvation type extraction mechanism, generally observed with neutral ligands such as TODGA. $^{33}$ TAM-4-DGA, used in the present case, is similar to TODGA in metal ion binding, and hence, the uptake profiles appear analogous.

As evident from Figure 5a, the $K_{\mathrm{d}}$ value of $\mathrm{Eu}^{3+}$ on the TAM-4-DGA resin was very large $(>200)$ even at $0.01 \mathrm{M}$ $\mathrm{HNO}_{3}$, which means that the stripping of the sorbed $\mathrm{Eu}^{3+}$ from the resin may not be possible with dilute acid. It necessitated, therefore, the use of a complexing agent for efficient stripping of the loaded $\mathrm{Eu}^{3+}$ from the resin phase. Due to this, we used 0.1 M HEDTA ( $N$-(2-hydroxyethyl)ethylenediamine triacetic acid) for back extraction of $\mathrm{Eu}^{3+}$, where its $K_{\mathrm{d}}$ value was $<10$. The advantage of using HEDTA is its large solubility even at high acid concentration $\left(3 \mathrm{M} \mathrm{HNO}_{3}\right)$, unlike EDTA which is soluble only above $\mathrm{pH} 3$.

To confirm the reusability and the stability of the TAM-4DGA resin, $\mathrm{Eu}^{3+}\left(0.1 \mathrm{mg} / \mathrm{mL}\right.$ at $\left.3 \mathrm{M} \mathrm{HNO}_{3}\right)$ was sorbed on the resin and desorbed with 0.1 M HEDTA in five successive cycles. After desorption of $\mathrm{Eu}^{3+}$, the resin was washed with water to remove the traces of HEDTA before starting the next cycle. As shown in Figure 5b, no change in the performance of the resin was observed in five successive cycles, confirming the excellent hydrolytic and leach stability of the resin.

The distribution coefficient values of actinide ions such as $\mathrm{UO}_{2}{ }^{2+}, \mathrm{Pu}^{4+}$, and $\mathrm{Am}^{3+}$, which are important from the radioactive waste management point of view, were also measured at $3 \mathrm{M} \mathrm{HNO}_{3}$ and are listed in Table 2. Whereas the extraction of the trivalent and tetravalent actinides was very large, the hexavalent uranium was poorly extracted. This behavior was previously reported for DGA ligands where the presence of two axial $\mathrm{O}$ atoms in $\mathrm{UO}_{2}{ }^{2+}$ gives rise to restrictions while coordinating with the bulky DGA ligand molecules. ${ }^{35}$ The $K_{d}$ values with the resins prepared by impregnating tripodal DGA ligand, T-DGA (Figure 1b), DGAfunctionalized calix[4]arene, C4DGA (Figure 1c), and bare DGA ligand (TODGA, Figure 1a) are also included in Table 2 for comparison. The results indicate that the highest extraction efficiency for trivalent actinides and lanthanides can be achieved by the TAM-4-DGA ligand. This feature has also been shown in solvent extraction where the highest extraction of trivalent actinides was found with the TAM-4-DGA ligand. ${ }^{27}$ These results indicated that the TAM-4-DGA ligand is a better candidate among various multiple DGA ligands for the recovery of trivalent actinide and lanthanide ions from acidic feed samples. Although the back extraction of trivalent actinides and lanthanides from the TAM-4-DGA resin phase seems to be nonviable with dilute acid (based on results shown 


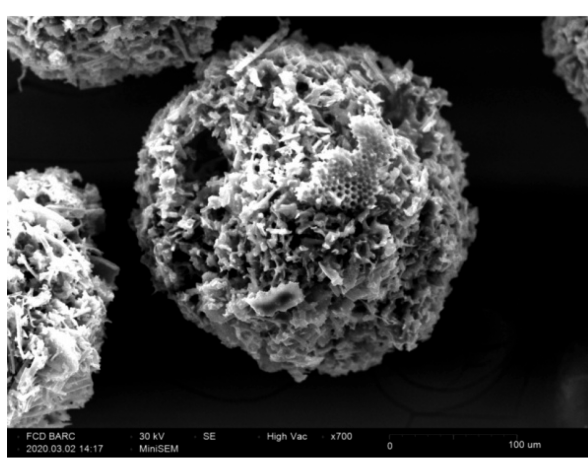

(a)

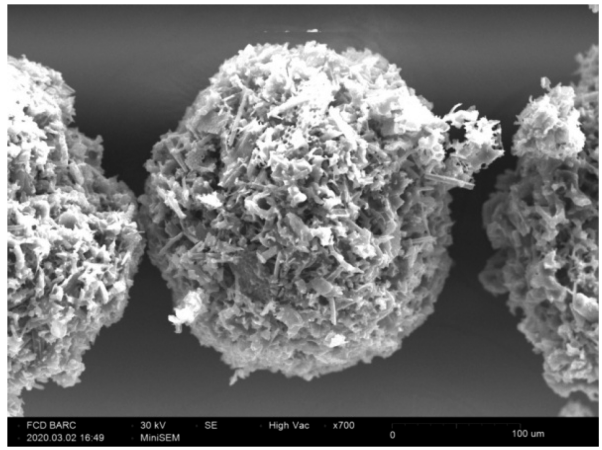

(b)

Figure 3. SEM images of (a) pristine Chromosorb-W and (b) Chromosorb-W loaded with the extractants (TAM-4-DGA) solution in 5\% isodecanol $+95 \% n$-dodecane.

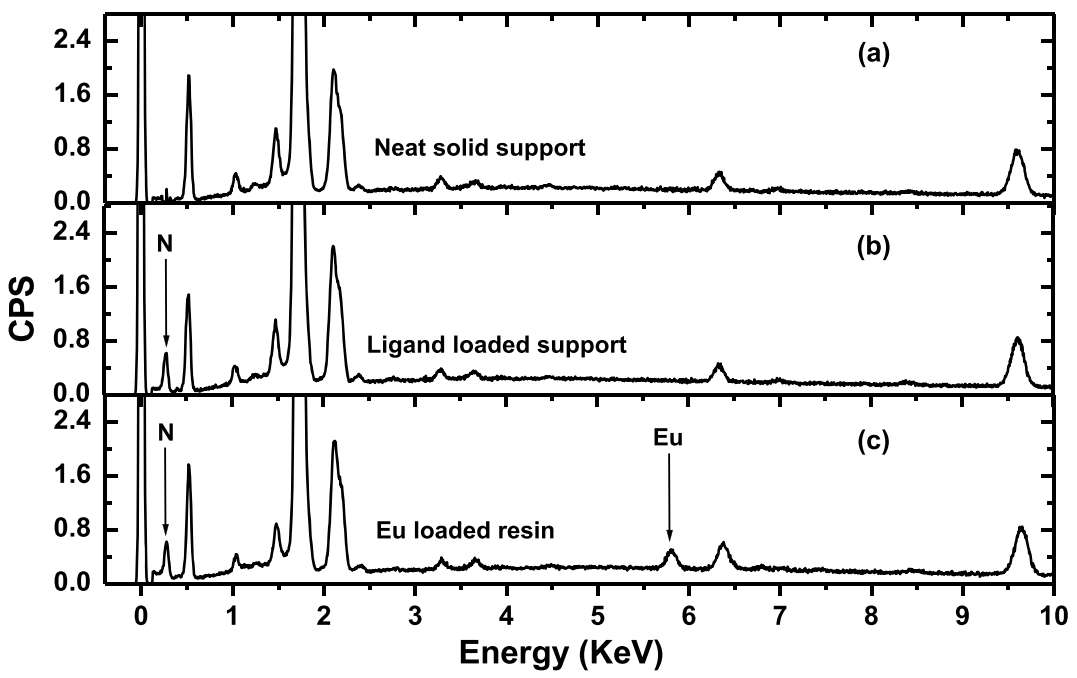

Figure 4. EDX spectra of (a) Chromosorb-W, (b) extraction chromatographic resin, and (c) Eu ${ }^{3+}$ loaded resin.
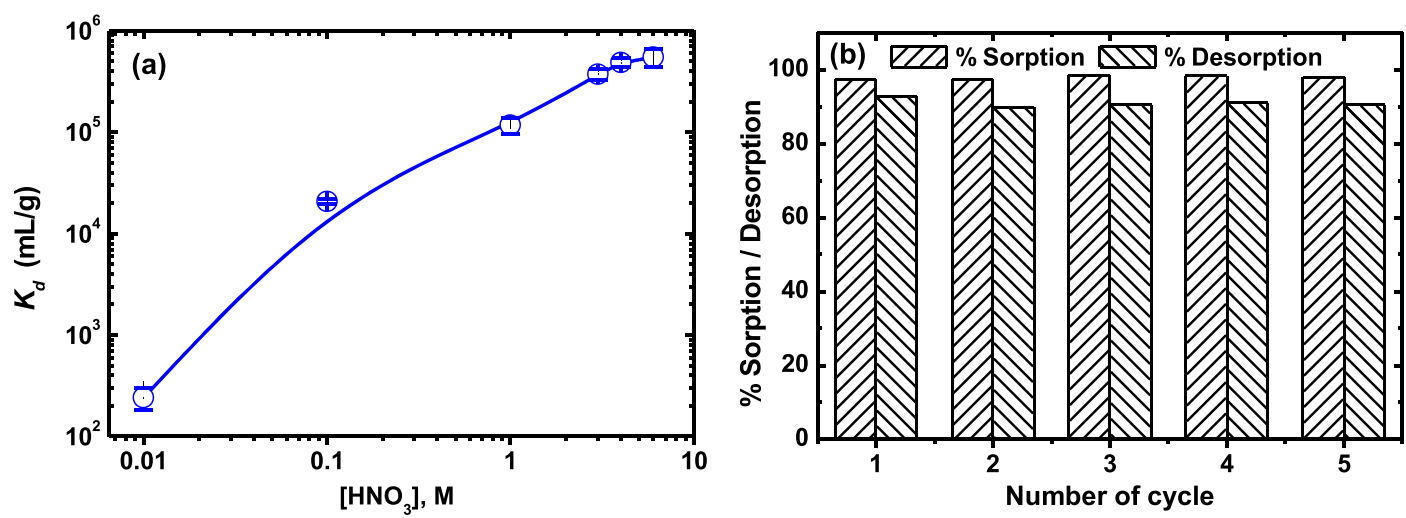

Figure 5. Uptake of $\mathrm{Eu}^{3+}$ onto the TAM-4-DGA resin. (a) Effect of feed acidity on the distribution coefficient $\left(K_{\mathrm{d}}\right)$ of Eu ${ }^{3+}$; $(\mathrm{b})$ sorption and desorption of $\mathrm{Eu}^{3+}$ on the resin in five successive cycles to establish the stability of the resin.

Table 2. Distribution Coefficient $\left(K_{\mathrm{d}}\right)$ Values of Metal Ions with Resins Prepared by Different DGA Ligands ${ }^{a}$

\begin{tabular}{|c|c|c|c|c|}
\hline \multirow[b]{2}{*}{ Metal ions } & \multicolumn{4}{|c|}{$K_{\mathrm{d}}$ at $3 \mathrm{M} \mathrm{HNO}_{3}$} \\
\hline & TAM-4-DGA $^{b}$ & T-DGA ${ }^{34, c}$ & $\mathrm{C} 4 \mathrm{DGA}^{34, d}$ & TODGA $^{11, e}$ \\
\hline $\mathrm{Eu}^{3+}$ & $(3.7 \pm 0.4) \times 10^{5}$ & $8335 \pm 410$ & $8330 \pm 380$ & 9018 \\
\hline $\mathrm{Am}^{3+}$ & $(4.3 \pm 0.4) \times 10^{5}$ & $9939 \pm 340$ & $6985 \pm 253$ & 7212 \\
\hline $\mathrm{Pu}^{4+}$ & $(2.9 \pm 0.3) \times 10^{5}$ & $4757 \pm 138$ & $5305 \pm 168$ & 5130 \\
\hline $\mathrm{UO}_{2}^{2+}$ & $10.6 \pm 2.1$ & $9.8 \pm 0.5$ & $0.50 \pm 0.31$ & 110 \\
\hline
\end{tabular}

${ }^{a}$ Aqueous phase: $3 \mathrm{M} \mathrm{HNO}_{3}$. Temperature: $25{ }^{\circ} \mathrm{C}{ }^{b}$ Ligand loading: $11 \%(\mathrm{w} / \mathrm{w}),{ }^{c} 10 \%(\mathrm{w} / \mathrm{w}),{ }^{d} 10 \%(\mathrm{w} / \mathrm{w}),{ }^{e} 47 \%(\mathrm{w} / \mathrm{w})$. 

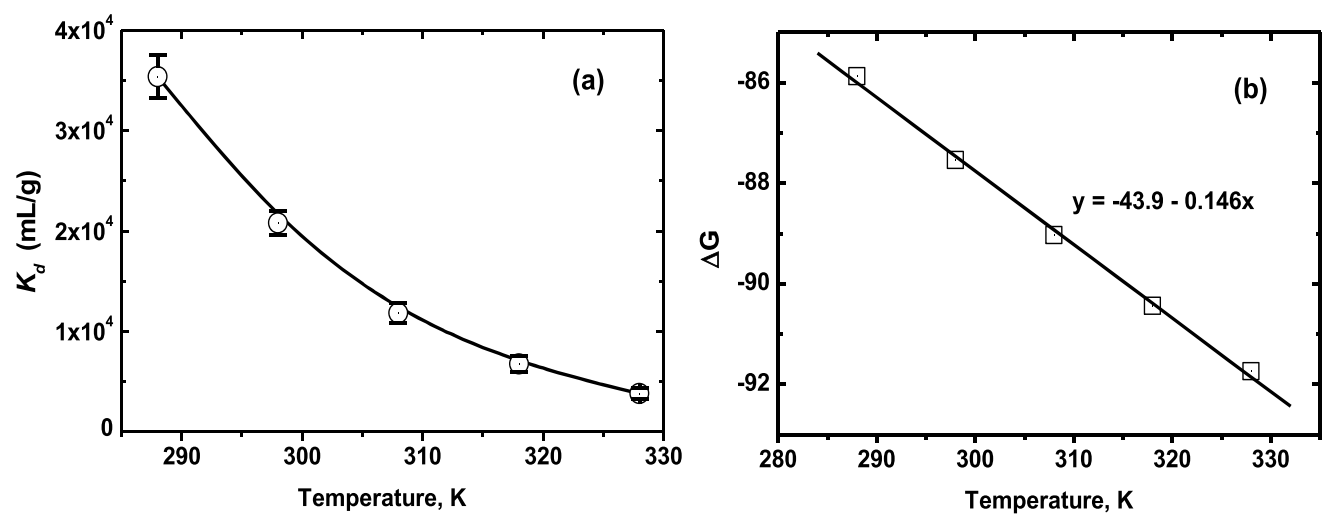

Figure 6. (a) Variation of $K_{\mathrm{d}}$ value of $\mathrm{Eu}^{3+}$ with temperature and (b) variation of $\Delta G$ with temperature; Aqueous phase: $0.1 \mathrm{M} \mathrm{HNO}_{3}$.
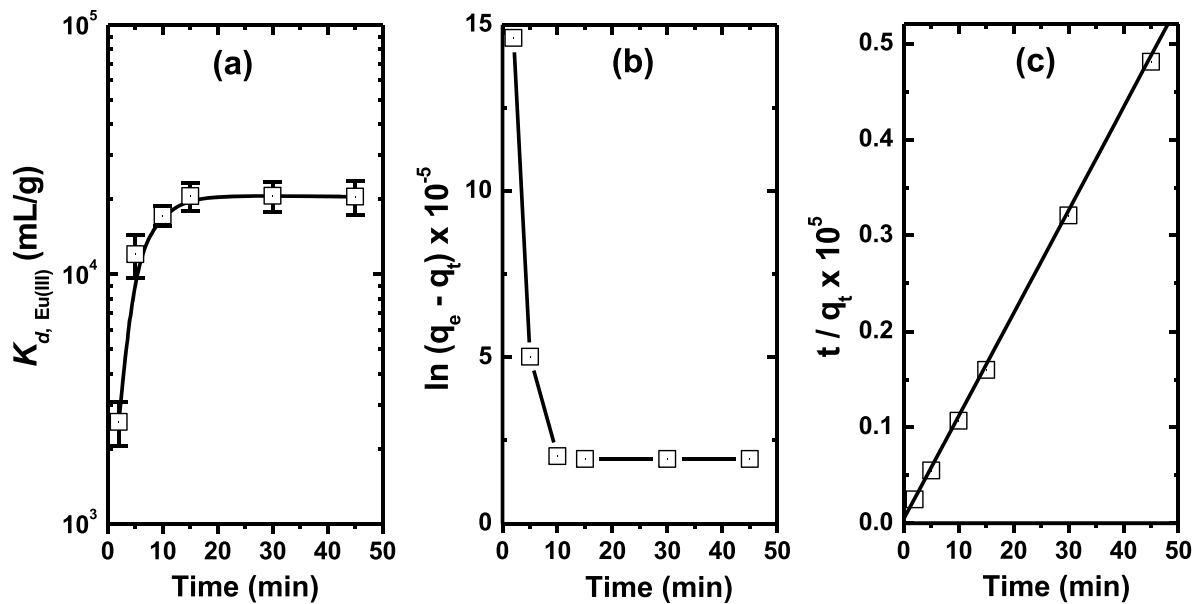

Figure 7. (a) Sorption behavior of $\mathrm{Eu}^{3+}$ as a function of time on the TAM-4-DGA resin. Aqueous phase: $0.1 \mathrm{M} \mathrm{HNO}_{3}$. (b) Kinetic data fitted in pseudo-first-order rate kinetic and (c) pseudo-second-order rate kinetic.

in Figure 5a), use of complexing solution like HEDTA can be employed for this purpose.

3.3. Thermodynamics of $\mathrm{Eu}^{3+}$ Sorption. To obtain the various thermodynamics parameters such as $\Delta G, \Delta H$, and $\Delta S$, it is desirable to have knowledge of the equilibrium reaction taking place between the ligand present on the resin and the $\mathrm{Eu}^{3+}$ ion in the aqueous phase. The equilibrium reaction for the distribution of $\mathrm{Eu}^{3+}$ on the resin can be described as

$$
\mathrm{Eu}_{(\mathrm{aq})}^{3+}+3 \mathrm{NO}_{3(\mathrm{aq})}{ }^{-}+\mathrm{xL}_{(\mathrm{s})} \stackrel{K_{\mathrm{ex}}}{\longleftrightarrow}\left[\left(\mathrm{Eu}\left(\mathrm{NO}_{3}\right)_{3} \cdot \mathrm{L}_{\mathrm{x}}\right]_{(\mathrm{s})}\right.
$$

where the subscripts (aq) = aqueous phase and $(\mathrm{s})=$ solid phase, and $\mathrm{L}=$ TAM-4-DGA ligand present on the solid support. Here, the term $\left[\left(\mathrm{Eu}\left(\mathrm{NO}_{3}\right)_{3} \cdot \mathrm{L}_{x}\right]_{(\mathrm{s})}\right.$ is the metal ligand complex that is extracted or sorbed onto the resin. For simplicity, this term will be represented as $[M \cdot L]_{(s)}$ in the subsequent text. The equilibrium constant, $K_{\mathrm{ex}}$ for the above equilibrium can be written as

$$
K_{\mathrm{ex}}=[\mathrm{M} \cdot \mathrm{L}]_{(\mathrm{s})} /\left\{\left[\mathrm{Eu}^{3+}\right]_{(\mathrm{aq})} \cdot\left[\mathrm{NO}_{3}^{-}\right]_{(\mathrm{aq})}^{3} \cdot[\mathrm{L}]_{(\mathrm{s})}^{x}\right\}
$$

Since, $K_{\mathrm{d}}=[\mathrm{M} \cdot \mathrm{L}]_{(\mathrm{s})} /\left[\mathrm{Eu}^{3+}\right]_{(\mathrm{aq})}$, the eq 7 can be solved as

$$
K_{\mathrm{d}}=K_{\mathrm{ex}} \cdot\left[\mathrm{NO}_{3}^{-}\right]_{(\mathrm{aq})}^{3} \cdot[\mathrm{L}]_{(\mathrm{s})}^{x}
$$

Converting the above equation into linear form, we obtain the following equation:

$$
\log K_{\mathrm{d}}=\log K_{\mathrm{ex}}+3 \log \left[\mathrm{NO}_{3}^{-}\right]_{(\mathrm{aq})}+x \log [\mathrm{L}]_{(\mathrm{s})}
$$

For the calculation of the $K_{\mathrm{ex}}$ value, it is essential to have the activities of nitrate ions in the aqueous phase and that of the ligand on the solid. Although the concentration of ligand on the solid is known, its activity is not known. In such case, the $K_{\text {ex }}$ shall be considered as the "conditional equilibrium constant" and its value was calculated from the known concentration of the ligand on solid phase and the nitrate ion concentration in the aqueous phase. In the equilibrium reaction 6 , the value of $x$ was taken as 2 based on the results obtained in slope analysis in solvent extraction as described in eq $9 .^{20}$ It is fairly good to assume a similar $\mathrm{Eu}^{3+} /$ ligand stoichiometry in extraction chromatography as observed in solvent extraction when the same solvent is used, for example ligand dissolved in $5 \%$ isodecanol $/ n$-dodecane. Additionally, both studies were carried out with the tracer metal ion concentration, and a similar correlation for the extraction of metal ions by solvent extraction and extraction chromatography has been shown earlier. ${ }^{8}$ Therefore, the value of the conditional equilibrium constant $\left(K_{\mathrm{ex}}\right)$ for equilibrium reaction 6 was calculated by assuming the composition of the extracted complex as $\left[\left(\mathrm{Eu}\left(\mathrm{NO}_{3}\right)_{3} \cdot \mathrm{L}_{2}\right]_{(\mathrm{s})}\right.$. From the calculated $K_{\mathrm{ex}}$ the value of the Gibb's free energy can be calculated using the standard relation $\left(\Delta G=-R T \ln K_{e x}\right)$.

To understand the thermodynamics of $\mathrm{Eu}^{3+}$ sorption on the TAM-4-DGA resin, the temperature dependence of the $K_{\mathrm{d}}$ values of $\mathrm{Eu}^{3+}$ was measured. As indicated in Figure 6a, $\mathrm{Eu}^{3+}$ ion sorption onto the resin was exothermic in nature which was evident by an exponential decrease in the $K_{d}$ values with 
rising temperature. From the $K_{\mathrm{d}}$ values, the value of $K_{\mathrm{ex}}$ was calculated at different temperatures to gain $\Delta G$ values $(\Delta G=$ $\left.-R T \ln K_{\mathrm{ex}}\right)$. The values of $\Delta S$ and $\Delta H$ were obtained by plotting $\Delta G$ vs $T(\Delta G=\Delta H-T \Delta S)$, which yielded the slope equal to $\Delta S$ and intercept equal to $\Delta H$. From Figure $6 \mathrm{~b}$, values of $\Delta H$ and $\Delta S$ were calculated as $-43.9 \pm 1.3 \mathrm{~kJ} / \mathrm{mol}$ and 146 $\pm 4 \mathrm{~J} / \mathrm{mol} / \mathrm{K}$, respectively, indicating that the sorption of $\mathrm{Eu}^{3+}$ onto the TAM-4-DGA resin was both enthalpy and entropy driven. A large positive entropy change is an indication of dehydration of the metal ion primary hydration sphere where coordinated water molecules are replaced by the complexing ligand. On the other hand, the enthalpy change during dehydration of the metal ion and metal/ligand complexation reaction makes the overall process exothermic.

3.4. Sorption Kinetic of $\mathrm{Eu}^{3+}$. To understand the kinetic model responsible for the sorption process, it was desirable to investigate the $\mathrm{Eu}^{3+}$ mass transfer from the aqueous phase to the resin phase with time. As shown in Figure 7a, the sorption kinetic was relatively fast and the equilibrium $K_{d}$ values were obtained within $15 \mathrm{~min}$ of shaking time. The kinetic was relatively faster in the present work as compared to other analogous extraction chromatographic resins prepared from DGA-based ligands such as T-DGA and C4DGA, where equilibrium was reached in about $45 \mathrm{~min}^{22}$ The sorption kinetic is dependent on the mass transfer rate, which is dependent on the complexation kinetic and the diffusion rate. If one assumes a similar complexation kinetic for TAM-4DGA, T-DGA, and C4DGA ligands, then the overall sorption kinetic shall depend on the diffusion of the complex from the surface of the resin to the core. Since the diffusion of the complex is strongly influenced by the viscosity of the medium, the difference in the composition of the solvent of the resins (TAM-4-DGA resin and T-DGA/C4DGA resins) may show different kinetic patterns. While the previously reported resins have the solvent composition of $10 \%(\mathrm{w} / \mathrm{w})$ ligand dissolved in $20 \%$ isodecanol $/ n$-dodecane, the present solvent composition was $11.1 \%(\mathrm{w} / \mathrm{w})$ ligand dissolved in $5 \%$ isodecanol $/ n$ dodecane. This difference in the solvent composition might have favored the sorption kinetic in the present work. Nonetheless, a plateau region after $15 \mathrm{~min}$ of equilibration (Figure $7 \mathrm{a}$ ) indicated that the $\mathrm{Eu}^{3+}$ ions sorbed on the resin were not desorbed even when the equilibration time was prolonged. In view of these observations, $30 \mathrm{~min}$ of shaking time were given for all the subsequent $K_{\mathrm{d}}$ measurements.

In order to investigate the type of kinetic followed, the sorption data were fitted in the pseudo-first-order and pseudosecond-order rate equations. ${ }^{23,24}$ As shown in Figure $7 \mathrm{~b}$, poor fitting of the data indicated the absence of a first-order rate kinetic in this case. Subsequently, when the data were fitted in the pseudo-second-order kinetic equation (eq 3), a straight line was obtained (Figure $7 \mathrm{~b}$ ). The value of $k_{2}$ was obtained as 6.33 $\times 10^{-7} \mathrm{~g} / \mathrm{cpm} \cdot \mathrm{min}$. As the fitting in the pseudo-second-order rate kinetic model was good, it was an indication that the interaction between the metal ion and the ligand on the resin was controlling the sorption process. This feature indicates that a monolayer of the $\mathrm{Eu}^{3+}$ ion is formed on the resin surface where it is chemically bonded with the ligands. To test this postulate, the Elovich model was used (eq 4) which states that, if a species is sorbed on the surface in a multilayer sorption process without its desorption, the rate of sorption will decrease with time due to an increase in the surface coverage. $^{36,37}$ As evident from Figure $8 \mathrm{a}$, a nonlinear plot of the Elovich equation supports the absence of the multilayer sorption phenomenon.
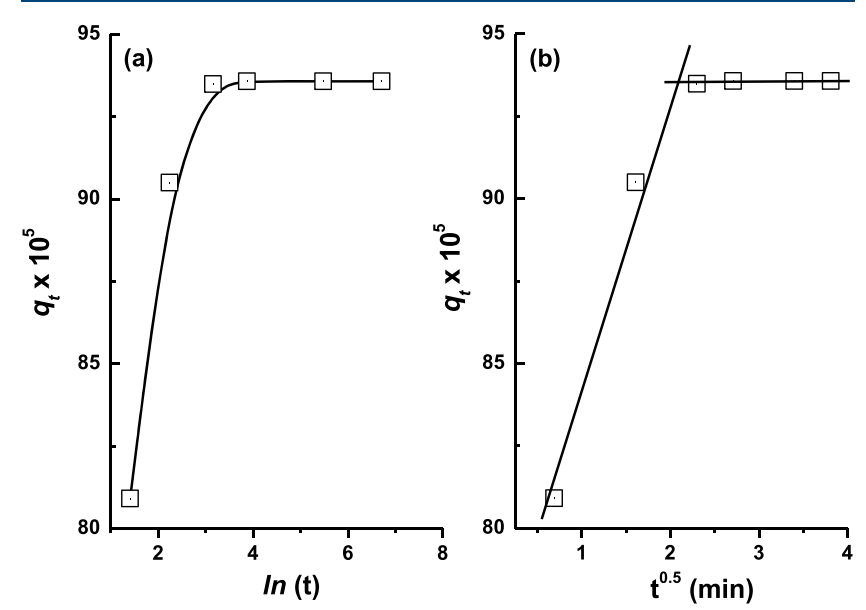

Figure 8. (a) Elovich kinetic model plot and (b) diffusion kinetic for the sorption of $\mathrm{Eu}^{3+}$ on TAM-4-DGA resins. Aqueous phase: $0.1 \mathrm{M}$ $\mathrm{HNO}_{3}$.

It is well understood that the metal ion sorption process onto extraction chromatographic resins involves a series of steps which can affect the sorption kinetic. It involves (i) diffusion of metal ions from the bulk aqueous phase to the surface of the solid sorbent, (ii) electrostatic interaction with the metal ion and the ligand at the boundary layer, and (iii) metal ligand complex diffusion from the surface of the resin bead into the pores of the solid matrix. In such processes, as the diffusion of a metal ion from the bulk solution to the boundary layer is rather fast, the rate-limiting step may be either the complexation (particularly for multiple DGA ligands) or the metal/ligand adduct diffusion into the pores of the solid matrix, commonly known as the pore diffusion process. ${ }^{38}$ Assuming that the complexation is rather fast, in view of the involvement of only one DGA arm in metal ion binding, ${ }^{20}$ the diffusion into the stationary phase pores is significant. To gain clarity on this phenomenon, the pore diffusion model (eq 5) was also tested. It is proposed ${ }^{39}$ that if the plot of $q_{t}$ vs $t^{0.5}$ in eq 5 gives a straight line, the sorption process is solely controlled by intraparticle diffusion. In contrast, if the linear fitting exhibits multilinear curves, two or more steps may be involved in the sorption process. In the present case (Figure $8 \mathrm{~b}$ ), the plot consists of two linear parts, which confirms that the sorption process proceeded at least by two sorption mechanisms: (i) the film diffusion and (ii) the intraparticle diffusion. The first part in Figure $8 b$ with a positive slope is an indication that the boundary-layer diffusion (film diffusion) is probably limiting the sorption process. On the other hand, the second part of the curve with a zero slope indicates that the pore diffusion is perhaps limiting the sorption process. The value $C$ (intercept of the Weber and Morris model) provides information about the thickness of the aqueous film around the solid resin. ${ }^{31}$ The positive $C$ value in this work is an indication of an intraparticle diffusion process. One of the important conclusions that can be noted from Figure $8 \mathrm{~b}$ is that the $q_{t}$ vs $t^{0.5}$ plot does not pass through the origin. This feature indicates that the intraparticle diffusion is probably not a rate-controlling step for the sorption of $\mathrm{Eu}^{3+}$. Thus one can conclude that the film and the intraparticle 
diffusion are concurrently operating for $\mathrm{Eu}^{3+}$ ion sorption from bulk solution to the solid phase.

3.5. Sorption Isotherm for $\mathrm{Eu}^{3+}$. To understand the interaction of the $\mathrm{Eu}^{3+}$ ion with the TAM-4-DGA ligand present on the surface of the solid, its sorption isotherm was investigated at $1 \mathrm{M} \mathrm{HNO}_{3}$. At equilibrium, the limiting sorption capacity of $\mathrm{Eu}^{3+}$ was $14.4 \pm 0.1 \mathrm{mg}$ per $\mathrm{g}$ of the resin that corresponds to $94.8 \mu$ mole of Eu/g resin. As mentioned above, $97 \mu \mathrm{mol}$ of TAM-4-DGA were present per $\mathrm{g}$ of the impregnated resin suggesting the formation of a $1: 1$ metal/ ligand complex. This contrasts with the results reported in solvent extraction studies where $\mathrm{Eu}^{3+}$ forms a 2:1 complex (ligand to metal). ${ }^{20}$ However, the comparison of the present result may not be justified as the solvent extraction results are reported on tracer metal concentrations, while in the present work excess metal concentration $(5 \mathrm{mg} / \mathrm{mL})$ was used to saturate the ligand.

The sorption data of $\mathrm{Eu}^{3+}$ on the resin were fitted in several popular isotherm models such as Langmuir, Freundlich, Temkin, and Dubinin-Radushkuvich $(\mathrm{D}-\mathrm{R})$ models given in Table 1. As shown in Figure 9a, the plot of $C_{\mathrm{e}} / q_{\mathrm{e}}$ vs $C_{\mathrm{e}}$ was a
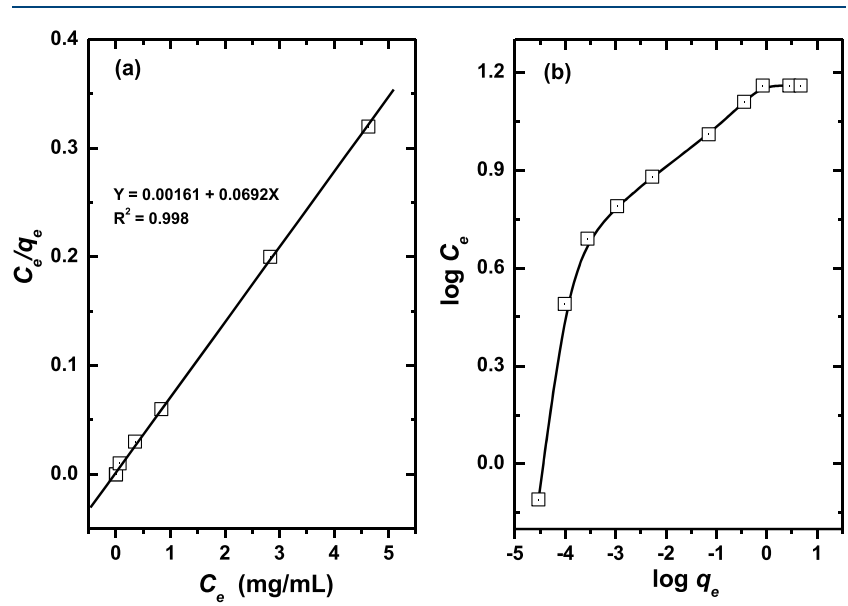

Figure 9. (a) Langmuir plot and (b) Freundlich plot for the sorption of $\mathrm{Eu}^{3+}$ on the TAM-4-DGA resin. Aqueous phase: $1 \mathrm{M} \mathrm{HNO}_{3}$.

straight line with a good fitting correlation coefficient. This behavior was an indication that the sorption followed the Langmuir monolayer sorption model. The value of $q_{\max }$ was $14.5 \pm 0.1 \mathrm{mg}$ of $\mathrm{Eu} / \mathrm{g}$ resin, which is in excellent agreement with the value obtained experimentally in the batch experiment $(14.4 \pm 0.1 \mathrm{mg} / \mathrm{g})$. The isotherm data were also treated for the multilayer sorption phenomenon in the Freundlich model (Table 1) which is based on multilayer coverage of the species on the surface of the extraction chromatographic resin. However, fitting data in the Freundlich model (Figure 9b) were poor, which gave an indication of the absence of the multilayer sorption phenomenon. To confirm this, the isotherm data were further fitted to the Temkin model (Table 1). The Temkin model considers that there are indirect interactions between the metal ions and the ligand present on the surface, and due to these indirect interactions, the sorption heat in different layers shall decrease linearly upon coverage. It means if the sorption data are fitting in the Temkin model, it would be an indication of the multilayer sorption process. However, poor fitting of the data in the Temkin isotherm equation (Figure 10a) further indicated the absence of multilayer sorption in this work.
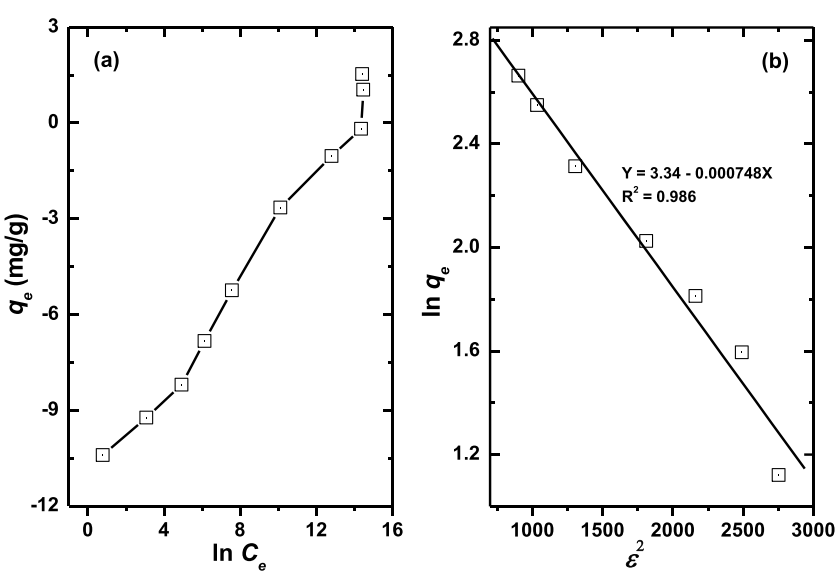

Figure 10. (a) Temkin and (b) D-R plots for the sorption of $\mathrm{Eu}^{3+}$ on the TAM-4-DGA resin. Aqueous phase: $1 \mathrm{M} \mathrm{HNO}_{3}$.

In order to distinguish the sorption process in the present work as either physisorption or chemisorption, the sorption data were fitted in the $\mathrm{D}-\mathrm{R}$ isotherm model (Table 1 ). The $\mathrm{D}-\mathrm{R}$ model assumes that if the sorbent surface is heterogeneous where all the sites are energetically equivalent and the sorption is monolayer in nature, then the mean sorption energy quantity $(\beta)$ is given as $E=1 /(-2 \beta)^{1 / 2}$. Here, $E=$ mean sorption energy which is the free energy needed for the transfer of $1 \mathrm{~mol}$ of metal ions from infinity to the surface of the sorbent. ${ }^{30}$ The energy in the present work was obtained to be $26 \pm 2 \mathrm{~kJ} / \mathrm{mol}$ (Figure 10b). The value of $E$ gives information about the type of sorption mechanism, chemisorption or physisorption. ${ }^{40}$ A value of $E>8 \mathrm{~kJ} / \mathrm{mol}$ signifies a chemisorption process, whereas a value $<8 \mathrm{~kJ} / \mathrm{mol}$ points to a physical sorption process. Since the numerical value of $E$ in the present work is $>8 \mathrm{~kJ} / \mathrm{mol}(25.8 \mathrm{~kJ} / \mathrm{mol})$, it indicates that the sorption of $\mathrm{Eu}^{3+}$ ions on the resin takes place via a chemical interaction. The chemical interaction between the $\mathrm{Eu}^{3+}$ cation and the TAM-4-DGA ligand present on the resin was further confirmed by the spectroscopic measurements described below.

3.6. Interaction of $\mathrm{Eu}^{3+}$ with Resin. To further investigate the chemical reaction between the $\mathrm{Eu}^{3+}$ cation and the TAM-4-DGA ligand present on the solid support, FTIR and luminescence spectroscopy were applied. As shown in Figure 11, a peak in the region $1580-1690 \mathrm{~cm}^{-1}$ in the FTIR spectra was an indication of the presence of the $>\mathrm{C}=\mathrm{O}$ group of the TAM-4-DGA ligand present in the impregnated resin (this peak was absent in the solid Chromosorb-W). Upon complexation with $\mathrm{Eu}^{3+}$, a clear shift in the $>\mathrm{C}=\mathrm{O}$ vibrational frequency was observed confirming a chemical interaction between the ligand and the $\mathrm{Eu}^{3+}$ ion.

To obtain further elaboration on the $\mathrm{Eu}^{3+} /$ ligand complexation, emission spectra were recorded and the lifetime of $\mathrm{Eu}^{3+}$ was measured both in the aqueous phase and on the resin. As shown in Figure 12, the band features in the emission spectra originate from the electronic transitions of the ${ }^{5} \mathrm{D}_{0}$ state to the ${ }^{7} \mathrm{~F}_{1}(589 \mathrm{~nm})$ and ${ }^{7} \mathrm{~F}_{2}(612 \mathrm{~nm})$ states of the $\mathrm{Eu}^{3+}$ ion. ${ }^{41}$ The ${ }^{5} \mathrm{D}_{0} \rightarrow{ }^{7} \mathrm{~F}_{2}$ band $(614 \mathrm{~nm})$ is hypersensitive in nature, and its intensity increases upon complexation with the ligand due to replacement of water molecules from the coordination sphere of $\mathrm{Eu}^{3+}$. On the other hand, the ${ }^{5} \mathrm{D}_{0} \rightarrow{ }^{7} \mathrm{~F}_{1}$ band $(590 \mathrm{~nm})$ remains unaffected during the complexation. The ratio of the peak intensity (or band area) due to the ${ }^{5} \mathrm{D}_{0} \rightarrow{ }^{7} \mathrm{~F}_{2}$ and 


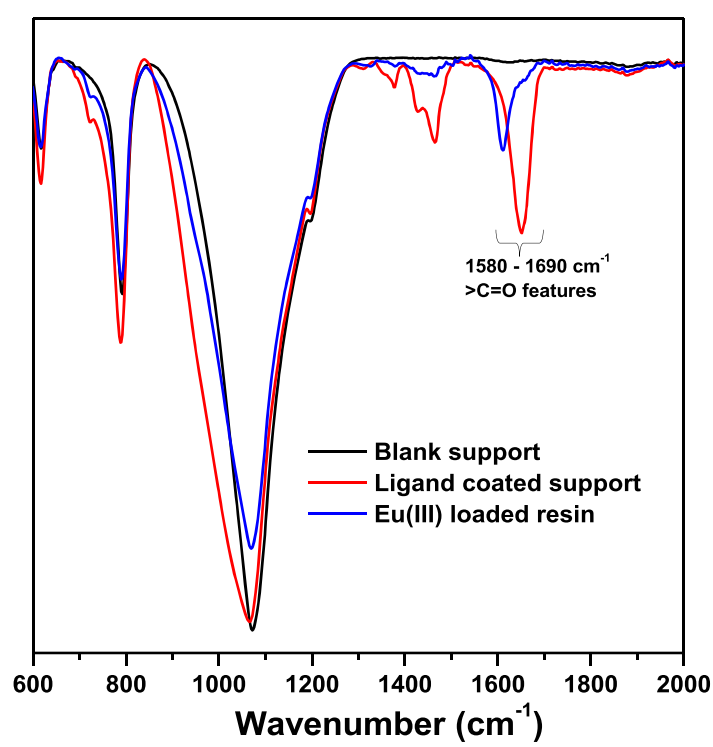

Figure 11. FTIR spectra of the blank solid support, ligand coated resin, and $\mathrm{Eu}^{3+}$ loaded resin.

${ }^{5} \mathrm{D}_{0} \rightarrow{ }^{7} \mathrm{~F}_{1}$ transition bands is referred to as the asymmetry factor and is generally used to understand the symmetry in the complex. ${ }^{42}$ In the present work, the asymmetry factor for the $\mathrm{Eu}^{3+}$ /aquo complex in $1 \mathrm{M} \mathrm{HNO}_{3}$ was found to be 1.34, which increased to 2.48 upon complexation with the ligand on the resin (Figure 12). In addition to this, splitting of the ${ }^{5} \mathrm{D}_{0} \rightarrow{ }^{7} \mathrm{~F}_{2}$ peak at $614 \mathrm{~nm}$ also indicates a symmetry change around the coordination sphere of the $\mathrm{Eu}^{3+}$ ion. The fluorescence decay lifetime of $\mathrm{Eu}^{3+}$ in $1 \mathrm{M} \mathrm{HNO}_{3}$ and on the resin was calculated to be 0.121 and $1.34 \mathrm{~ms}$, respectively (Figure 12). The number of water molecules in the first coordination sphere of the free $\mathrm{Eu}^{3+}$ ion was calculated from the lifetime data using the Barthelemy-Choppin equation: ${ }^{43}$

$$
N_{\mathrm{H}_{2} \mathrm{O}}=(1.05 / \tau)-0.7
$$

where $\tau$ is the lifetime in ms. $8.0 \mathrm{H}_{2} \mathrm{O}$ molecules were present in the inner coordination sphere of $\mathrm{Eu}^{3+}$ in the $1 \mathrm{M} \mathrm{HNO}_{3}$ solution. These water molecules were successfully replaced by the ligands upon complexation, as indicated by the absence of
$\mathrm{H}_{2} \mathrm{O}$ molecules in the complexed $\mathrm{Eu}^{3+}$ on the resin. This feature further confirms the chemical interaction between the $\mathrm{Eu}^{3+}$ ion and the ligand present on the resin during the sorption process.

3.7. Column Studies. After investigating the interaction of $\mathrm{Eu}^{3+}$ with the TAM-4-DGA resin, column studies were taken up to evaluate its application feasibility for separation of lanthanides. Figure 13 shows the loading, washing, and elution

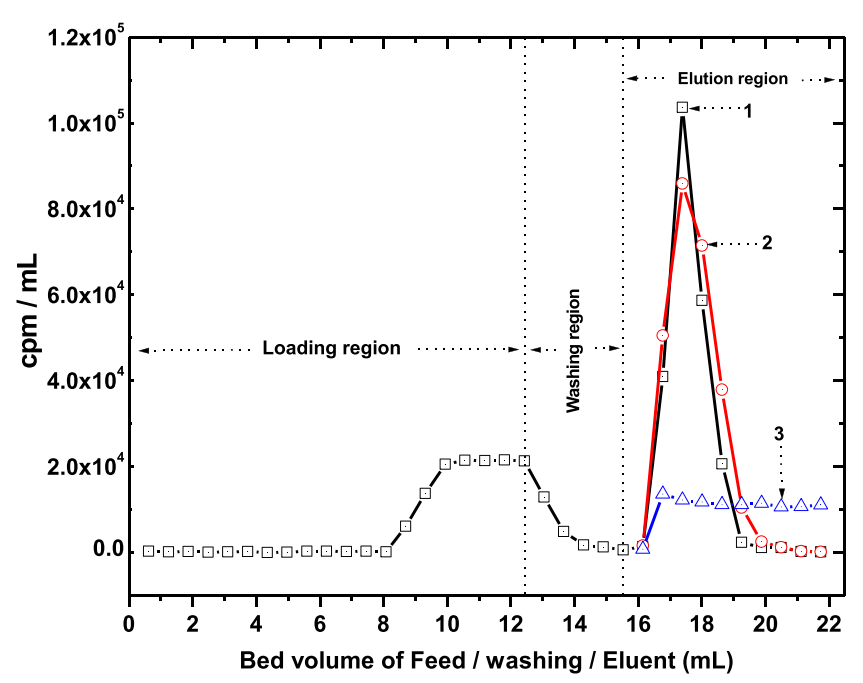

Figure 13. Loading, washing, and elution curves for $\mathrm{Eu}^{3+}$ on the TAM-4-DGA resin column. Feed solution: $0.40 \mathrm{mg} / \mathrm{mL} \mathrm{Eu}^{3+}$ at $3 \mathrm{M}$ $\mathrm{HNO}_{3}$. Washing solution: $3 \mathrm{M} \mathrm{HNO}_{3}$. Eluent: (1) $1 \mathrm{M}$ guanidine carbonate +0.05 M EDTA, (2) 0.1 M HEDTA, (3) distilled water. Column dead volume: $1.0 \mathrm{~mL}$. Flow rate: $0.3 \mathrm{~mL} / \mathrm{min}$.

profile of $\mathrm{Eu}^{3+}$ on the column. The breakthrough of $\mathrm{Eu}^{3+}$ was observed after passing $13 \mathrm{~mL}$ of the feed solution. After removing the dead volume of the column $(1 \mathrm{~mL})$, the amount of $\mathrm{Eu}^{3+}$ loaded on the column was found to be $12.0 \mathrm{mg} / \mathrm{g}$ of resin. Since the $\mathrm{Eu}^{3+}$ capacity by the resin obtained in batch static experiments was $14.4 \mathrm{mg} / \mathrm{g}$, it indicates that the column capacity was about $83 \%$ of the resin capacity. It is worth mentioning that the column loading capacity is governed by several factors such as the column bed height, flow rate, and
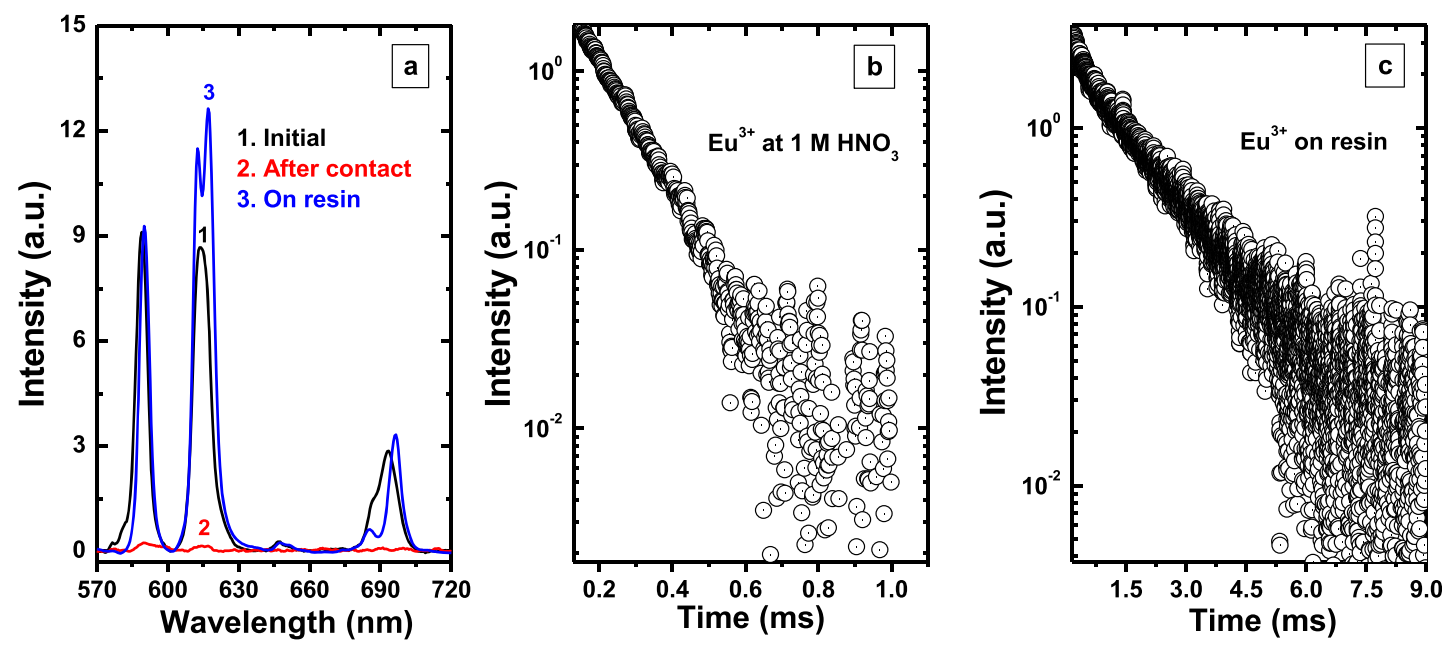

Figure 12. (a) Emission spectra and (b) fluorescence decay curve of $\mathrm{Eu}^{3+}$ ion in the aqueous phase and (c) decay profile of Eu $\mathrm{u}^{3+}$ ion loaded onto the resin. Excitation: 396 nm. Emission: 614 nm. 
reaction kinetic between the metal ion and the ligand on the resin, and any variation in these factors may affect the column loading capacity significantly.

After loading the column to close to $100 \%$ of the breakthrough value, it was washed with $3 \mathrm{M} \mathrm{HNO}_{3}$ to remove the physically sorbed or uncomplexed $\mathrm{Eu}^{3+}$ from the column followed by its elution. Elution of the loaded $\mathrm{Eu}^{3+}$ was carried out with three different solutions. Initially, distilled water was used as the eluent (curve 3 in Figure 13), which led to only about $40 \%$ elution in $10 \mathrm{~mL}$. This feature indicates the inefficiency of water as the eluent for the back extraction of the sorbed $\mathrm{Eu}^{3+}$ from this column. Taking a clue from the literature, ${ }^{44}$ we used a complexing buffer for elution, which comprised $1 \mathrm{M}$ guanidine carbonate $+0.05 \mathrm{M}$ EDTA dissolved in water. As shown by the elution curve 1, complete recovery of $\mathrm{Eu}^{3+}$ was possible in about $10 \mathrm{~mL}$ of this eluent. However, this buffer solution created bubbles in the column due to neutralization of the acid present in the column which led to the slowing down of the flow rate, gradually resulting in the choking of the column. It was decided, therefore, not to use this buffer mixture as eluent particularly when the column is loaded with acid. However, it can be used for a column where the loading is done at very low acidity, e.g. $\mathrm{pH} 3$ solution. ${ }^{44,45}$ As an alternate eluent $0.1 \mathrm{M}$ HEDTA was used as the complexing agent which yielded a similar elution curve (curve 2) to that of the guanidine carbonate, but without any physical problem of the column. The mass balance of the loaded $\mathrm{Eu}^{3+}$ and the eluted $\mathrm{Eu}^{3+}$ was within $\pm 4 \%$. It is worth mentioning that HEDTA is a homologue of EDTA where one carboxylic acid group is replaced with a hydroxyl group which enhances its water solubility even at large concentrations of acid ( $>6 \mathrm{M}$ $\mathrm{HNO}_{3}$ ), unlike EDTA which precipitated below $\mathrm{pH} 3$.

\section{CONCLUSIONS}

A diglycolamide-functionalized tetraaza-12-crown-4 (TAM-4DGA) based extraction chromatographic resin was studied for its sorption behavior for $\mathrm{Eu}^{3+}$ ion. With only $11 \%(\mathrm{w} / \mathrm{w})$ loading of the ligand on the solid support, the $K_{\mathrm{d}}$ value of $\mathrm{Eu}^{3+}$ was large enough in a wide acidity range (0.1-6 $\left.\mathrm{M} \mathrm{HNO}_{3}\right)$ suggesting its possible application for the separation of trivalent actinides and lanthanides from a wide range of feed acidity. The sorption kinetic was fast and required only about $15 \mathrm{~min}$ to attain equilibrium. The kinetic modeling of the data suggested a pseudo-second-order model. The sorption of $\mathrm{Eu}^{3+}$ followed the Langmuir monolayer model with a sorption energy of $26 \pm 2 \mathrm{~kJ} / \mathrm{mol}$, which is an indication of chemisorption. The chemical interaction between the $\mathrm{Eu}^{3+}$ cation and the ligand on the resin was confirmed by FTIR and fluorescence spectroscopy. The sorption of $\mathrm{Eu}^{3+}$ on the resin was exothermic with a $\Delta H$ value of $-43.9 \pm 1.3 \mathrm{~kJ} / \mathrm{mol}$. The results suggest that the present extraction chromatographic resin material can be used for the separation of trivalent lanthanides as well as actinides from radioactive waste feeds as well as lean solutions such as environmental samples. However, the major shortcoming of this resin is the need for a complexing agent for eluting the loaded metal ions from the resin phase which necessitates the need for a suitable ligand which can give efficient extraction of metal ions and also efficient back extraction with mineral acids.

\section{AUTHOR INFORMATION}

\section{Corresponding Authors}

Prasanta K. Mohapatra - Homi Bhabha National Institute, Mumbai 400094, India; Radiochemistry Division, Bhabha Atomic Research Centre, Mumbai 400085, India; ○ orcid.org/0000-0002-0577-1811; Email: mpatra@ barc.gov.in; Fax: +91-22-25505151

Willem Verboom - Laboratory of Molecular Nanofabrication, MESA+ Institute for Nanotechnology, University of Twente, 7500 AE Enschede, The Netherlands; 이이.org/00000002-6863-8655; Email: w.verboom@utwente.nl; Fax: +91-22-25505151

\section{Authors}

Piyali Banerjee - PREFRE Lab, Nuclear Recycles Board, BARC, Tarapur, Maharashtra 401502, India; Homi Bhabha National Institute, Mumbai 400094, India

Seraj A. Ansari - Homi Bhabha National Institute, Mumbai 400094, India; Radiochemistry Division, Bhabha Atomic Research Centre, Mumbai 400085, India; (으이.org/ 0000-0002-2242-6876

Richard J.M. Egberink - Laboratory of Molecular Nanofabrication, MESA+ Institute for Nanotechnology, University of Twente, 7500 AE Enschede, The Netherlands

Srirangaraja Ramasubramanium - PREFRE Lab, Nuclear Recycles Board, BARC, Tarapur, Maharashtra 401502, India

Chhagan B. Patil - PREFRE Lab, Nuclear Recycles Board, BARC, Tarapur, Maharashtra 401502, India

Jurriaan Huskens - Laboratory of Molecular Nanofabrication, MESA+ Institute for Nanotechnology, University of Twente, 7500 AE Enschede, The Netherlands; (1) orcid.org/0000-0002-4596-9179

Complete contact information is available at: https://pubs.acs.org/10.1021/acs.iecr.1c00186

\section{Notes}

The authors declare no competing financial interest.

\section{ACKNOWLEDGMENTS}

The authors (P.B., S.A.A., P.K.M.) are grateful to Dr. P. K. Pujari, Director, Radiochemistry \& Isotope Group, for his constant encouragement.

\section{REFERENCES}

(1) Wada, K.; Yoshikawa, T.; Murata, M. Decontamination work in the area surrounding Fukushima Dai-ichi nuclear power plant: Another occupational health challenge of the nuclear disaster. Arch. Environ. Occup. Health 2012, 67, 128-132.

(2) Measurement of Radionuclides in Food and Environment; Guidebook, Technical Report Series No. 295; IAEA, Vienna, 1989; p 70.

(3) Sill, C. W.; Puphal, K. W.; Hindman, F. D. Simultaneous determination of alpha-emitting nuclides of radium through californium in soil. Anal. Chem. 1974, 46, 1725-1737.

(4) Chieco, N. A. Environmental measurements procedure manual HASL-300; U.S. Department of Energy, New York, NY, 1990.

(5) Hill, C. Development of highly selective compounds for solvent extraction processes: partitioning and transmutation of long-lived radionuclides from spent nuclear fuels. In: Advanced separation techniques for nuclear fuel reprocessing and radioactive waste treatment; Nash, K. L., Lumetta, G. J., Eds.; Woodhead Publishing: U.K., 2011; pp 311-362. 
(6) Mokhodoeva, O. B.; Myasoedova, G. V.; Zakharchenko, E. A. Solid-phase extractants for radionuclide pre-concentration and separation. New possibilities. Radiochemistry 2011, 53, 35-43.

(7) Risticevic, S.; Niri, V. H.; Vuckovic, D.; Pawliszyn, J. Recent developments in solid-phase micro-extraction. Anal. Bioanal. Chem. 2009, 393, 781-795.

(8) Horwitz, E. P.; McAlister, D. R.; Dietz, M. L. Extraction chromatography versus solvent extraction: How similar are they? Sep. Sci. Technol. 2006, 41, 2163-2182.

(9) Horwitz, E. P.; Chiarizia, R.; Dietz, M. L.; Diamond, H.; Nelson, D. M. Separation and preconcentration of actinides from acidic media by extraction chromatography. Anal. Chim. Acta 1993, 281, 361-372. (10) Mohapatra, P. K.; Sriram, S.; Manchanda, V. K.; Badheka, L. P. Uptake of metal ions by extraction chromatography using dimethyl dibutyl tetradecyl-1,3-malonamide (DMDBTDMA) as the stationary phase. Sep. Sci. Technol. 2000, 35, 39-55.

(11) Ansari, S. A.; Pathak, P. N.; Husain, M.; Prasad, A. K.; Parmar, V. S.; Manchanda, V. K. Extraction chromatographic studies of metal ions using $N, N, N^{\prime}, N^{\prime}$-tetraoctyl diglycolamide as the stationary phase. Talanta 2006, 68, 1273-1280.

(12) Van Hecke, K.; Modolo, G. Separation of actinides from low level liquid wastes (LLLW) by extraction chromatography using novel DMDOHEMA and TODGA impregnated resins. J. Radioanal. Nucl. Chem. 2004, 261, 269-275.

(13) Horwitz, E. P.; McAlister, D. R.; Bond, A. H.; Barrans, R. E. Novel extraction of chromatographic resins based on tetraalkyl diglycolamides: Characterization and potential applications. Solvent Extr. Ion Exch. 2005, 23, 319-344.

(14) Janczewski, D.; Reinhoudt, D. N.; Verboom, W.; Hill, C.; Allignol, C.; Duchesne, M.-T. Tripodal diglycolamides as highly efficient extractants for f-elements. New J. Chem. 2008, 32, 490-495.

(15) Leoncini, A.; Mohapatra, P. K.; Bhattacharyya, A.; Raut, D. R.; Sengupta, A.; Verma, P. K.; Tiwari, N.; Bhattacharyya, D.; Jha, S.; Wouda, A. M.; Huskens, J.; Verboom, W. Unique selectivity reversal in $\mathrm{Am}^{3+}-\mathrm{Eu}^{3+}$ extraction in a tripodal TREN-based diglycolamide in ionic liquid: extraction, luminescence, complexation and structural studies. Dalton Trans. 2016, 45, 2476-2484.

(16) Leoncini, A.; Ansari, S. A.; Mohapatra, P. K.; Boda, A.; Ali, S. M.; Sengupta, A.; Huskens, J.; Verboom, W. Benzene-centered tripodal diglycolamides: synthesis, metal ion extraction, luminescence spectroscopy, and DFT studies. Dalton Trans. 2017, 46, 1431-1438.

(17) Leoncini, A.; Ansari, S. A.; Mohapatra, P. K.; Sengupta, A.; Huskens, J.; Verboom, W. Diglycolamide-functionalized poly(propylene imine) diaminobutane dendrimers for sequestration of trivalent f-elements: synthesis, extraction and complexation. Dalton Trans. 2017, 46, 501-508.

(18) Mohapatra, P. K.; Iqbal, M.; Raut, D. R.; Verboom, W.; Huskens, J.; Godbole, S. V. Complexation of novel diglycolamide functionalized calix[4]arenes: Unusual extraction behaviour, transport, and fluorescence studies. Dalton Trans. 2012, 41, 360-363.

(19) Li, C.; Wu, L.; Chen, L.; Yuan, X.; Cai, Y.; Feng, W.; Liu, N.; Ren, Y.; Sengupta, A.; Murali, M. S.; Mohapatra, P. K.; Tao, G.; Zeng, H.; Ding, S.; Yuan, L. Highly efficient extraction of actinides with pillar[5] arene-derived diglycolamides in ionic liquids via a unique mechanism involving competitive host-guest interactions. Dalton Trans. 2016, 45, 19299-19310.

(20) Bhattacharyya, A.; Egberink, R. M.; Mohapatra, P. K.; Verma, P. K.; Kanekar, A. S.; Yadav, A. K.; Jha, S. N.; Bhatacharyya, D.; Huskens, J.; Verboom, W. Remarkable enhancement in extraction of trivalent $f$-block elements using a macrocyclic ligand with four diglycolamide arms: Synthesis, extraction and spectroscopic and density functional theory studies. Inorg. Chem. 2019, 58, 1488514899 .

(21) Mendham, J.; Denny, R. C.; Barnes, J. D.; Thomas, M.; Sivasankar, B. Vogel's Textbook of quantitative chemical analysis, 6th ed.; Pearson Education Ltd.; New Delhi, 2009; pp 332-335.

(22) Ansari, S. A.; Mohapatra, P. K.; Iqbal, M.; Huskens, J.; Verboom, W. Two novel extraction chromatographic resins containing multiple diglycolamide-functionalized ligands: Preparation, characterization and actinide uptake properties. J. Chromatogr. A 2014, 1334, 79-86.

(23) Singh, D. B.; Prasad, G.; Rupainwar, D. C.; Singh, V. N. As(III) removal from aqueous solution by adsorption. Water, Air, Soil Pollut. 1988, 42, 373-386.

(24) Hameed, B. H.; Tan, I. A. W.; Ahmad, A. L. Adsorption isotherm, kinetic modeling and mechanism of 2,4,6-trichlorophenol on coconut husk-based activated carbon. Chem. Eng. J. 2008, 144, $235-244$.

(25) Langmuir, I. The adsorption of gases on plane surfaces of glass, mica and platinum. J. Am. Chem. Soc. 1918, 40, 1361.

(26) White, D. M.; Pilon, T. A.; Woolard, C. Biological treatment of cyanide containing wastewater. Water Res. 2000, 34, 2105-2109.

(27) McKay, G.; Blair, H. S.; Gardner, J. R. Adsorption of dyes on chitin. I. Equilibrium studies. J. Appl. Polym. Sci. 1982, 27, 3043.

(28) Arami, M.; Limaee, N. Y.; Mahmoodi, N. M. Investigation on the adsorption capability of egg shell membrane towards model textile dyes. Chemosphere 2006, 65, 1999-2008.

(29) Dubinin, M. M. The potential theory of adsorption of gases and vapors for adsorbents with energetically non-uniform surfaces. Chem. Rev. 1960, 60, 235-241.

(30) Polanyi, M. Theories of the adsorption of gases. A general survey and some additional remarks. Trans. Faraday Soc. 1932, 28, $316-333$.

(31) El Nemr, A. Potential of pomegranate husk carbon for Cr(VI) removal from wastewater: Kinetic and isotherm studies. J. Hazard. Mater. 2009, 161, 132-141.

(32) Gujar, R. B.; Ansari, S. A.; Mohapatra, P. K. Actinide ion uptake from acidic radioactive feeds using an extraction chromatographic resin containing a branched dialkyl amide. J. Chromatogr. A 2021, 1635, 461728.

(33) Ansari, S. A.; Mohapatra, P. K. A review on solid phase extraction of actinides and lanthanides with amide based extractants. $J$. Chromatogr. A 2017, 1499, 1-20.

(34) Ansari, S. A.; Mohapatra, P. K.; Iqbal, M.; Huskens, J.; Verboom, W. Two novel extraction chromatography resins containing multiple diglycolamide-functionalized ligands: Preparation, characterization and actinide uptake properties. J. Chromatogr. A 2014, 1334, $79-86$.

(35) Ansari, S. A.; Pathak, P. N.; Mohapatra, P. K.; Manchanda, V. K. Chemistry of diglycolamides: Promising extractants for actinide partitioning. Chem. Rev. 2012, 112, 1751-1772.

(36) Chien, S. H.; Clayton, W. R. Application of Elovich equation to the kinetics of phosphate release and sorption in soils. Soil Sci. Soc. Am. J. 1980, 44, 265-268.

(37) Ho, Y. S.; McKay, G. Application of kinetic models to the sorption of copper(II) on to peat. Adsorpt. Sci. Technol. 2002, 20, $797-815$.

(38) Gujar, R. B.; Ansari, S. A.; Mohapatra, P. K. Highly efficient composite polysulfone beads containing a calix[4]arene-mono-crown6 ligand and room temperature ionic liquid for radio-cesium separations: Remediation of environmental samples. Ind. Eng. Chem. Res. 2016, 55, 12460-12466.

(39) Guibal, E.; Milot, C.; Tobin, J. M. Metal-anion sorption by chitosan beats: Equilibrium and kinetic studies. Ind. Eng. Chem. Res. 1998, 37, 1454-1463.

(40) Alley, E. R. Water Quality Control Handbook, Vol. 8; McGraw Hill: 2000; pp 125-141.

(41) Binnemans, K. Interpretation of europium(III) spectra. Coord. Chem. Rev. 2015, 295, 1-45.

(42) Zhang, P.; Kimura, T. Complexation of Eu(III) with dibutyl phosphate and tributyl phosphate. Solvent Extr. Ion Exch. 2006, 24, 149-163.

(43) Barthelemy, P. P.; Choppin, G. R. Luminescence study of complexation of europium and dicarboxylic acids. Inorg. Chem. 1989, 28, 3354-3357.

(44) Gujar, R. B.; Ansari, S. A.; Verboom, W.; Mohapatra, P. K. Multi-podant diglycolamides and room temperature ionic liquid 
impregnated resins: An excellent combination for extraction chromatography of actinides. J. Chromatogr. A 2016, 1448, 58-66.

(45) Gujar, R. B.; Ansari, S. A.; Mohapatra, P. K. Spectacular enhancements in actinide ion uptake using novel extraction chromatography resins containing TODGA and ionic liquid. Sep. Purif. Technol. 2015, 141, 229-234. 